\title{
The Effect of Magnesium Sulfate on Postoperative Pain in Upper Limb Surgeries by Supraclavicular Block Under Ultrasound Guidance
}

\author{
Reza Akhondzade, ${ }^{1,}$ Sholeh Nesioonpour, ${ }^{1}$ Mohammadreza Gousheh, ${ }^{2}$ Farhad Soltani, ${ }^{2}$ and Mohsen \\ Davarimoghadam ${ }^{3}$ \\ ${ }^{1}$ Associate Professor of Anesthesiology, Department of Anesthesiology, Pain Research Center, Ahvaz Jundishapur University of Medical Sciences, Ahvaz, Iran \\ ${ }^{2}$ Assistant Professor of Anesthesiology, Department of Anesthesiology, Pain Research Center, Ahvaz Jundishapur University of Medical Sciences, Ahvaz, Iran \\ ${ }^{3}$ Anesthesiologist, Department of Anesthesiology, Pain Research Center, Ahvaz Jundishapur University of Medical Sciences, Ahvaz, Iran \\ "Corresponding author: : Reza Akhondzade, Department of Anesthesiology, Pain Research Center, Ahvaz Jundishapur University of Medical Sciences, Imam Khomeini Hospital, \\ Azadegan Ave, Ahvaz, Iran. Tel/Fax: +98-6132220168, E-mail: rezaakh@hotmail.com
}

Received 2017 January 02; Revised 2017 March 13; Accepted 2017 March 26.

\begin{abstract}
Background: Previous studies have been conducted to evaluate the effect of different adjuvants on brachial plexus block. Objectives: This study investigated the effect of adding magnesium sulfate to lidocaine on postoperative pain in upper limb surgeries by supraclavicular brachial plexus block under ultrasound guidance.

Methods: This study was carried out on patients who were candidate for upper limb surgeries. This was a controlled double-blind study conducted on a number of 52 patients aged 18 - 75 years with ASA class I or II. The first group (M) received lidocaine $1 \%$ ( $4 \mathrm{mg} / \mathrm{kg}$ ) plus fentanyl 50 micg and magnesium sulfate $20 \%(5 \mathrm{~mL}$ ) while the second group $(\mathrm{N})$ received lidocaine $1 \%$ ( $4 \mathrm{mg} / \mathrm{kg}$ ) plus fentanyl 50 micg and normal saline $(5 \mathrm{~mL})$ to supraclavicular brachial plexus block under ultrasound guidance. Postoperative pain was evaluated by visual analog scale(VAS) until 24 hours. Sensory and motor blocks onset and duration, rescue analgesics, hemodynamic variables, and side effects were recorded for all the patients.

Results: Postoperative VAS values at 24 hours were significantly lower in group M than group N $(\mathrm{P}<0.0001)$. Sensory and Motor blocks onset and duration were statistically longer in group $\mathrm{M}$ than group $\mathrm{N}(\mathrm{P}<0.0001)$.

Conclusions: The addition of magnesium sulfate to lidocaine decreased the postoperative pain and increased the onset and duration of sensory and motor blocks in supraclavicular brachial plexus block under ultrasound guidance in upper limb surgeries.
\end{abstract}

Keywords: Magnesium Sulfate, Postoperative Pain, Supraclavicular Block, Ultrasound

\section{Background}

Effective postoperative analgesia improves patient's outcome in terms of early ambulation, decreased complications, and reduced incidence of postoperative chronic pain (1). Regional anesthesia is a safe and effective method for upper limb surgeries. This method can prolong analgesia and reduce postoperative pain (2). Nowadays, peripheral nerve block has found an important role in anesthesiology. Safety and high success rate have made it a common technique in outpatient and inpatient anesthesia. Upper limb surgeries are mostly performed under peripheral nerve blocks such as brachial plexus block (3). Brachial plexus may be blocked in the level above the clavicle as interscalene and supraclavicular blocks or below the clavicle as infraclavicular and axillary blocks (4). Supraclavicular brachial plexus block is used for surgeries of the upper limb below the arm, from elbow to hand. Brachial plexus is blocked in the level between trunks and divisions. In this level, a small volume of local anesthetic is needed for reliable block. The guide of ultrasound allows the anesthesiologist to see the subclavian artery as a bold marker and neural structures around it above the 1st rib (5). Under ultrasound guidance, performing peripheral nerve blocks decreases the complications associated with blind techniques such as intravascular injection, pneumothorax, hematoma, etc., by better visualization of local anesthetic spread, leading to a decrease in the amount of local anesthetic to provide anesthesia. Patients develop severe pain after the end of local anesthetic effects; therefore, increasing the duration of local anesthetics is important (6). Lidocaine is an aminoamide, moderate acting local anesthetic that blocks the peripheral afferents acting on voltage-dependent sodium channels. Local anesthetics provide good anesthesia in regional blocks, but have shorter duration of postoperative analgesia. Thereby, various adjuncts like opioids, clonidine, neostigmine, dexamethasone, dexmedetomidine, ketorolac, ketamine, and low-level laser therapy, have been used in regional blocks to achieve desirable analgesia $(3,7,8)$. Magnesium sulfate is an N-methyl D-aspartate (NMDA) receptor antagonist in the central nervous system (CNS) and peripheral

Copyright (c) 2017, Anesthesiology and Pain Medicine. This is an open-access article distributed under the terms of the Creative Commons Attribution-NonCommercial 4.0 International License (http://creativecommons.org/licenses/by-nc/4.0/) which permits copy and redistribute the material just in noncommercial usages, provided the original work is properly cited. 
nervous system (PNS). The NMDA receptor complex contains binding sites for antagonists such as magnesium. Magnesium is used as adjuvant in peripheral nerve block $(9,10)$. Anti-nociceptive effects of magnesium are due to the regulation of calcium influx into the cell and antagonism of the NMDA receptors. Many clinical studies have demonstrated that magnesium used during general anesthesia reduced anesthetic requirement and postoperative rescue analgesic. Magnesium has been commonly used as antihypertensive agent. Magnesium may prevent postoperative shivering (11). More recently, it has been shown that magnesium sulfate decreased the effects of aminoamide local anesthetics on rat sciatic nerves in vivo. Hence, based on this paradoxical data, currently magnesium cannot be recommended as an adjuvant to enhance nerve blocks and needs to further studies (12).

\section{Objectives}

Improving the effects of local anesthetics in regional blocks and management of postoperative acute pain are important for patients after surgeries. Various supraclavicular brachial plexus block methods and anatomical variations in the brachial plexus call for more studies. This study was designed to evaluate the effect of magnesium sulfate as an adjuvant on postoperative pain in upper limb surgeries by supraclavicular brachial plexus block under ultrasound guidance.

\section{Methods}

This randomized controlled, double blind clinical trial study was carried out after obtaining approval from the ethical committee of Ahvaz Jundishapour University of Medical Sciences (ethical approval number: IR.AJUMS.REC.1395.61) and registering the proposal of the study in the Iranian Research Clinical Trials center (IRCT2016051727954N1). The study setting was Imam Khomeini Hospital that is a trauma center in the southwest area of the country in the period between April and October 2016. From patients scheduled for upper limb orthopedic surgery (with traumatic fractures and tendon damages), 52 patients aged between 18 and 75 years, of both sexes, and with ASA class I or II (as inclusion criteria) were prospectively enrolled in this study. Exclusion criteria included: patient's refusal, hypersensitivity to drugs of study, coagulopathy, local skin site infection, traumatic nerve injury of upper limb, and any drugs or opium abuse. On entering the patient in the operation room, basic monitoring was applied (such as ECG, pulse oximeter, and noninvasive blood pressure monitoring), and baseline parameters were recorded. Details of anesthesia technique and study protocol as well as visual analog scale $(0=$ no pain and $10=$ worst pain imaginable $)$ were explained to the patients. Written informed consent was obtained from all the patients. An intravenous (IV) line (20G catheter) was inserted in the contralateral upper limb. IV infusion of normal saline $5 \mathrm{~mL} / \mathrm{kg}$ was started and oxygen was given at $3 \mathrm{~L} / \mathrm{min}$ via face mask. All the patients received midazolam $0.03 \mathrm{mg} / \mathrm{kg}$ and fentanyl $3 \mathrm{mcg} / \mathrm{kg}$ as IV premedication. For randomization, 52 flash cards (26 M and $26 \mathrm{~N}$ ) were made and mixed in a box, and given to the nurse in the operation room. Any patient participating in the study referred to the nurse and received one flash card. The chosen flash card was sent out of the cycle and not allowed to be used again. Thereby, the patients were randomly divided into two groups; the first Group (M) received $4 \mathrm{mg} / \mathrm{kg}$ lidocaine 1\% (Aburaihan Co., Iran) plus 50 micg fentanyl plus $5 \mathrm{~mL}$ magnesium sulfate 20\% (Pasteur Institute, Iran), and the second group (N) received $4 \mathrm{mg} / \mathrm{kg}$ lidocaine $1 \%$ plus 50 micg fentanyl plus $5 \mathrm{~mL}$ normal saline $0.9 \%$. The dose of magnesium sulfate was determined based on previous studies $(1,12)$. The nurse of operation room prepared the drug components. Before procedure, the patients were placed in the supine position with their head turned to contralateral side. The supraclavicular area was cleaned using an antiseptic iodine solution and draped. The anesthesiologist performing supraclavicular block was unaware of the constituents of the drugs and group allotments. Similarly, research assistants keeping records of different parameters including VAS score were also unaware of group allotment and drugs used in the block. Thus, blinding was properly maintained. To perform supraclavicular blockade, the ultrasound apparatus (EdgeTM Mini-Dock, FUJIFILM Sonosite, WA 98021 USA) was applied to see the brachial plexus at the level between trunks and divisions. A linear array ultrasound transducer was used in the study. After infiltration of the site of needle insertion by local anesthetic, a sterile $45 \mathrm{~mm}, 22 \mathrm{G}$ needle (Sonoplex ${ }^{\circledR}$, B. Braun, Germany) under ultrasound guidance was inserted and after reaching the tip of the needle near the subclavian artery around the brachial plexus, solution was injected and spread of drug was visualized. The continuous aspiration and injection was taken to avoid intravascular injection. After performing the block on the patients, hemodynamic parameters and all complications related to supraclavicular block (pneumothorax, hematoma, hypotension, bradycardia, etc.) were recorded. After completing the block, the surgery started. In order to evaluate the sensory block, pinprick test was used every 5 minutes until total analgesia was obtained in all the four nerves (median, ulnar, radial, and musculocutaneous) distributions. The data were recorded as follows: $0=$ no 
block, 1 = partial block, and 2 = complete loss of sensation to pinprick. Motor evaluation was performed by using a three-point scale test ( 2 = normal movement, $1=$ paresis with some movement possible, and $0=$ total paralysis). Motor and sensory blocks were recorded every 5 minutes for the first 30 minutes, then every 10 minutes for another 30 minutes, and every 15 minutes till end of the surgery. After the end of motor block, the patient had complete movement. The end of sensory block was defined as pain sensation with pinprick test. After finishing surgery and removal of the patients to the recovery room, research assistants completed the questionnaires of study. When the operation was over, VAS score was measured at 0 , $1,2,4,8,16$, and 24 hours. Meperidine $0.2 \mathrm{mg} / \mathrm{kg}$ was given intravenously when VAS $>3 \mathrm{~cm}$. The raw data were entered into a MicroSoft Excel spreadsheet and analyzed using standard statistical software SPSS, version 22.00 (SPSS Inc., Chicago, IL, USA). We performed Shapiro-wilk test for normality of the data distribution. The Chi-square test and sample t-test were used to analyze data. The data were summarized as mean \pm standard deviation or as minimum and maximum or percentages. P-value of less than 0.05 was considered significant. Generalized estimating equations (GEE) models were used to determine the relationship between the type of medicine and alterations in VAS score, blood pressure, and heart rate at different time points of study. GEE models consisted of two main effects: type of medicine and time point, and relationship between them.

\section{Results}

A number of 52 patients participated in the study that equally distributed in two groups; one group (M) received lidocaine plus magnesium and the other group $(\mathrm{N})$ received lidocaine plus normal saline. Table 1 shows the demographic data of both groups ( $\mathrm{M}$ and $\mathrm{N}$ ). There were no statistical differences in the demographic data of the patients between the two groups. Hemodynamic variables (blood pressure and heart rate) were stable in all the patients of both groups. None of the patients had severe complications and none of them were excluded from the study. Motor and sensory blocks characteristics of both groups ( $\mathrm{M}$ and $\mathrm{N}$ ) are shown in Table 2. During postoperative period, the patients were monitored for pain using VAS score at various time intervals till 24 hours (Table 3 ). Rescue analgesic was given when pain score was VAS $>3 \mathrm{~cm}$. The mean duration of analgesia (when patients demanded the first dose of rescue analgesia) was $8.00 \pm 0.00$ hours in the case group $\mathrm{M}$ and $4.26 \pm 1.88$ hours in the control group $\mathrm{N}$. The mean dose of rescue analgesic (meperidine) consumption in 24 hours was $17.50 \pm 5.00 \mathrm{mg}$ in the case group $\mathrm{M}$ and
$22.89 \pm 7.69 \mathrm{mg}$ in control group $\mathrm{N}$. Comparison of the VAS score in the case group $\mathrm{M}$ and control group $\mathrm{N}$ at different time points till 24 hours after surgery is illustrated in Figure 1. Hemodynamic parameters remained stable and similar in the two groups at all the measurement intervals. The pattern of mean Systolic Blood Pressure alterations in the case group $\mathrm{M}$ and control group $\mathrm{N}$ had no significant differences $(P=0.13)$. Also, the pattern of mean Diastolic Blood Pressure alterations in the case group $\mathrm{M}$ and control group $\mathrm{N}$ had no significant differences $(\mathrm{P}=0.62)$. The pattern of mean Heart Rate alterations in the case group $M$ and control group $\mathrm{N}$ had no significant differences $(\mathrm{P}=0.38)$. The patients were monitored for side effects and complications after supraclavicular block till 24 hours. In group M, one patient (3.8\%) and in group $\mathrm{N}$ three patients (11.5\%) had Nausea after supraclavicular brachial plexus block. One patient in each group (3.8\%) had Hematoma in the site of injection in supraclavicular brachial plexus block.

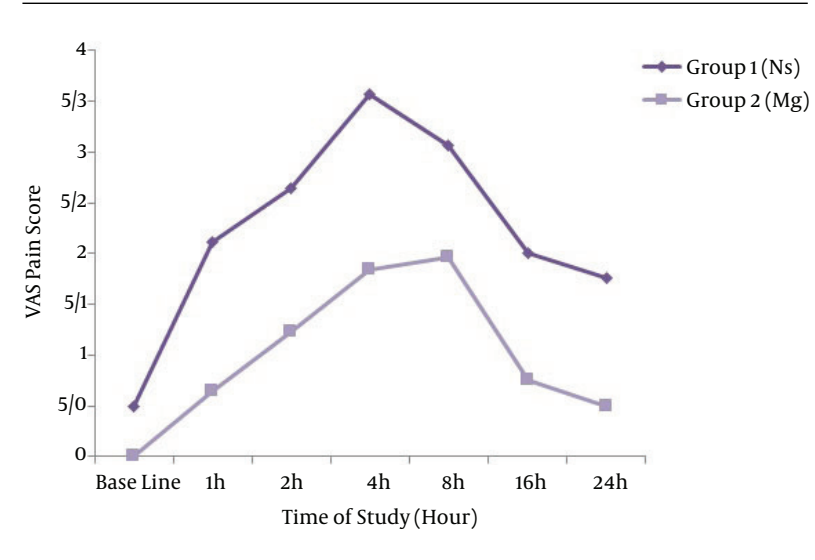

Figure 1. Time-Series Comparison of the VAS Score in the Two Groups

Table 1. Baseline Characteristics of the Participants ${ }^{\mathrm{a}, \mathrm{b}}$

\begin{tabular}{lccc}
\hline Characteristics & Group $\mathbf{N}(\mathbf{N}=\mathbf{2 6})$ & Group $\mathbf{M}(\mathbf{N}=\mathbf{2 6})$ & P Value \\
\hline Gender, No. (\%) & & 1.00 \\
\hline Female & $8(30.8)$ & $8(30.8)$ & \\
Male & $18(69.2)$ & $18(69.2)$ & \\
Age, $\mathbf{y}$ & $37.03 \pm 12.23$ & $36.65 \pm 13.93$ & 0.91 \\
\hline Height, $\mathbf{c m}$ & $172.50 \pm 9.33$ & $172.03 \pm 9.91$ & 0.86 \\
\hline Weight, $\mathbf{k g}$ & $75.26 \pm 10.77$ & $75.61 \pm 14.77$ & 0.92 \\
\hline $\begin{array}{l}\text { a Data are expressed as mean } \pm \text { SD unless otherwise stated. } \\
\text { b Group N: Lidocaine + Normal saline; group M: Lidocain + Magnesium. }\end{array}$
\end{tabular}


Table 2. Sensory and Motor Block Characteristics of the Participants

\begin{tabular}{|c|c|c|c|}
\hline Characteristics & Group $N(N=26)$ & Group $M(N=26)$ & P Value \\
\hline Rescue Analgesic (\%) & & & $<0.0001$ \\
\hline Yes & $19(84.6)$ & $4(26.9)$ & \\
\hline No & $7(15.4)$ & $22(73.1)$ & \\
\hline Sensory Block Onset, min & $10.07 \pm 1.68$ & $14.23 \pm 2.23$ & $<0.0001$ \\
\hline Sensory Block Duration, min & $103.81 \pm 8.09$ & $123.38 \pm 6.72$ & $<0.0001$ \\
\hline Motor Block Onset, min & $17.59 \pm 1.84$ & $23.00 \pm 2.13$ & $<0.0001$ \\
\hline Motor Block Duration, min & $80.25 \pm 6.80$ & $92.80 \pm 7.33$ & $<0.0001$ \\
\hline
\end{tabular}

${ }^{\mathrm{a}}$ Data are expressed as mean \pm SD unless otherwise stated.

Table 3. VAS During 24 Hours After Surgery Between the Two Study Groups ${ }^{\mathrm{a}}$

\begin{tabular}{|c|c|c|c|c|c|c|c|c|}
\hline \multirow[t]{2}{*}{ Variables } & \multicolumn{7}{|c|}{ Time points of Study, h } & \multirow[t]{2}{*}{ PValue $^{\text {b }}$} \\
\hline & Baseline & $\mathbf{1}$ & 2 & 4 & 8 & 16 & 24 & \\
\hline VAS & & & & & & & & $<0.0001$ \\
\hline Group N & $0.50(0.12)$ & $2.11(0.13)$ & $2.65(0.13)$ & $3.57(0.16)$ & $3.07(0.17)$ & $2.00(0.09)$ & $1.76(0.10)$ & \\
\hline Group M & $0(0)^{c}$ & $0.65(0.12)^{c}$ & $1.23(0.16)^{c}$ & $1.84(0.17)^{c}$ & $1.96(0.26)^{c}$ & $0.76(0.14)^{c}$ & $0.50(0.10)^{c}$ & \\
\hline
\end{tabular}

${ }^{\mathrm{a}}$ The values are expressed as mean (SE).

${ }^{\mathrm{b}}$ The P-value for Group-Time interaction (Based on the results of GEE analysis)

${ }^{\mathrm{c}} \mathrm{P}<0.05$ for statistical difference between the two groups at the same time-points.

\section{Discussion}

This study showed that the addition of $5 \mathrm{~mL}$ magnesium sulfate $20 \%$ to lidocaine increased the duration of analgesia and reduced postoperative pain in supraclavicular brachial plexus block under ultrasound guidance in upper limb surgeries, as well as delayed the analgesic request after surgery. In this study, we found that magnesium sulfate caused retardation in onset of sensory and motor blocks, but increased the duration of sensory and motor blocks in supraclavicular brachial plexus block under ultrasound guidance in upper limb surgeries. Magnesium sulfate had no effect on hemodynamic variables in supraclavicular brachial plexus block under ultrasound guidance in upper limb surgeries. In this study, the most complication after supraclavicular brachial plexus block under ultrasound guidance in upper limb surgeries was "Nausea". Rao et al. in Andhra Pradesh, India, in 2015, concluded in one study that the addition of magnesium sulfate to $0.5 \%$ bupivacaine in supraclavicular brachial plexus block for upper limb surgeries increased the duration of sensory and motor blocks in comparison with the use of $0.5 \%$ bupivacaine, although the change was not statistically significant (2). Haghighi et al. in Guilan, Iran, in 2014, investigated the effect of magnesium in axillary brachial plexus block when added to lidocaine in upper limb surg- eries, and reported that the addition of magnesium sulfate to lidocaine significantly increased the duration of sensory and motor blocks in comparison with the use of lidocaine alone (13). Abdelfatah et al. in Cairo, Egypt, in 2013, demonstrated that, the addition of magnesium sulfate to lidocaine in interscalene brachial plexus block significantly increased analgesic duration and reduced postoperative pain and opioid requirements in shoulder arthroscopic acromioplasty (14). Lee et al. in Seoul, Korea, in 2011, found out that, magnesium sulfate added to bupivacaine for interscalene brachial plexus block reduced postoperative pain in arthroscopic repair of rotator cuff(15). Previous studies were conducted with magnesium doses of 150,300, 450 , and $600 \mathrm{mg}$ and their authors proposed to increase the dose of magnesium in future. Hence, we conducted this study with magnesium dose of $1000 \mathrm{mg}$ and observed the increased effects of magnesium that is in line with previous investigations. Further studies need to be carried out using other adjuvants in low-level laser therapy, and various local anesthetics in different peripheral nerve blocks under ultrasound guidance. 


\section{Acknowledgments}

This paper was extracted from the thesis of Dr. Mohsen Davarimoghadam. We gratefully acknowledge the anesthesia residents, nursing staff, as well as the Anesthesiology and Orthopedics Departments and Pain Research Center at Ahvaz Jundishapur University of Medical Sciences and Imam Khomeini Hospital, for all their effort and support of this study.

\section{Footnotes}

Authors' Contribution: Study concept and design, Reza Akhondzade; Analysis and interpretation of data, Sholeh Nesioonpour; statistical analysis, Mohsen Davarimoghadam; study supervision, Reza Akhondzade.

Funding/Support: The financial support was provided by vice chancellor for research and technology, Ahvaz Jundishapur University of Medical Sciences.

\section{References}

1. Imani F. Postoperative pain management. Anesth Pain Med. 2011;1(1):67. doi: 10.5812/kowsar.22287523.1810. [PubMed: 25729647].

2. Rao LN, Jeyalakshmi V, Nagaraju M, Anitha S. The effect of magnesium sulfate as an adjuvant to $0.5 \%$ bupivacaine on motor and sensory supraclavicular brachial plexus blockade. Int J Basic Clin Pharmacol. $2015 ; 4(2): 317-21$.

3. Mukherjee K, Das A, Basunia SR, Dutta S, Mandal P, Mukherjee A. Evaluation of Magnesium as an adjuvant in Ropivacaine-induced supraclavicular brachial plexus block: A prospective, double-blinded randomized controlled study. J Res Pharm Pract. 2014;3(4):123-9. doi: 10.4103/2279-042X.145387. [PubMed: 25535620].

4. Hebl JR, Dilger JA, Byer DE, Kopp SL, Stevens SR, Pagnano MW, et al. A pre-emptive multimodal pathway featuring peripheral nerve block improves perioperative outcomes after major orthopedic surgery. Reg Anesth Pain Med. 2008;33(6):510-7. [PubMed: 19258965].
5. Brodner G, Van Aken H, Gogarten W. [Regional anesthesia for postoperative pain control]. Anasthesiol Intensivmed Notfallmed Schmerzther. 2007;42(1):32-41. doi: 10.1055/s-2007-969042. [PubMed: 17253335].

6. Fahmy NG, Ahmed DM, Sameer GM. A comparative study between the addition of MgSO4against dexamethasone to bupivacaine in the prolongation of ultrasound-guided interscalene nerve block for shoulder arthroscopy. Ain-Shams J Anaesthesiol. 2015;8(3):402. doi: 10.4103/1687-7934.161719.

7. Nesioonpour S, Akhondzadeh R, Mokmeli S, Moosavi S, Mackie M, Naderan M. Does low-level laser therapy enhance the efficacy of intravenous regional anesthesia? Pain Res Manag. 2014;19(6):e154-8. doi: 10.1155/2014/314910. [PubMed: 24945286].

8. Mirkheshti A, Saadatniaki A, Salimi A, Manafi Rasi A, Memary E, Yahyaei $\mathrm{H}$. Effects of dexmedetomidine versus ketorolac as local anesthetic adjuvants on the onset and duration of infraclavicular brachial plexus block. Anesth Pain Med. 2014;4(3):e17620. doi: 10.5812/aapm.17620. [PubMed: 25237638].

9. Dickenson AH. NMDA receptor antagonists: interactions with opioids. Acta Anesthesiol Scand. 1997;41(1):112-5. doi: 10.1111/j.13996576.1997.tb04624.x.

10. Faiz SH, Rahimzadeh P, Sakhaei M, Imani F, Derakhshan P. Anesthetic effects of adding intrathecal neostigmine or magnesium sulphate to bupivacaine in patients under lower extremities surgeries. J Res Med Sci. 2012;17(10):918-22. [PubMed: 23825989].

11. Faiz SH, Rahimzadeh $\mathrm{P}$, Imani $\mathrm{F}$, Bakhtiari A. Intrathecal injection of magnesium sulfate: shivering prevention during cesarean section: a randomized, double-blinded, controlled study. Korean J Anesthesiol. 2013;65(4):293-8. doi: 10.4097/kjae.2013.65.4.293. [PubMed: 24228140].

12. Vadhanan P, Tripaty DK, Adinarayanan S. Physiological and pharmacologic aspects of peripheral nerve blocks. J Anaesthesiol Clin Pharmacol. 2015;31(3):384-93. doi: 10.4103/0970-9185.161679. [PubMed: 26330722].

13. Haghighi M, Soleymanha M, Sedighinejad A, Mirbolook A, Naderi Nabi B, Rahmati M, et al. The effect of magnesium sulfate on motor and sensory axillary plexus blockade. Anesth Pain Med. 2015;5(1) doi: 10.5812/aapm.21943

14. Abdelfatah AM, Elshaer AN. The effect of adding magnesium sulfate to lidocaine in an interscalene plexus block for shoulder arthroscopic acromioplasty. Ain-Shams J Anesthesiol. 2014;7(1):59. doi: 10.4103/16877934.128416.

15. Lee AR, Yi HW, Chung IS, Ko JS, Ahn HJ, Gwak MS, et al. Magnesium added to bupivacaine prolongs the duration of analgesia after interscalene nerve block. Can J Anaesth. 2012;59(1):21-7. doi:10.1007/s12630011-9604-5. [PubMed: 22012543] 